\title{
Preparado microbiano con actividad ácido láctica como acelerante biológico en los procesos de fermentación para alimento animal
}

\section{Microbial preparation with lactic acid activity (lab) as biological accelerant in the fermentation process to feed cattle}

Fecha de recepción: 18 de junio de 2016

Fecha de aprobación: 23 de noviembre de 2016
Luis Miguel Borrás-Sandoval ${ }^{1}$

Elaine Cristina Valiño-Cabrera ${ }^{2}$

Carlos Eduardo Rodríguez-Molano ${ }^{3}$

\begin{abstract}
Resumen
El objetivo de este trabajo fue desarrollar un preparado microbiano a partir de un yogurt elaborado con base en un cultivo de bacterias ácido lácticas $(B A L)$ heterofermentativas de mediana y rápida acidificación (Lactobacillus delbrueckii ssp. bulgaricus y Streptococcust hermophilus), provenientes de un cultivo comercial liofilizado (Liofast Y452B, SACCO ${ }^{\circledR}$ ). Para el pH del preparado microbiano se realizó análisis de ANOVA, medido en 6 tiempos de fermentación (0, 6, 12, 24, 36 y 48 horas) con tres repeticiones. La elaboración del inóculo parte de la elaboración del yogurt; se preparó con leche entera de vaca, se calentó a $45^{\circ} \mathrm{C}$ y se inoculó con el cultivo de bacterias lácticas; el producto final de este presentó un $\mathrm{pH}$ de 4,63 a las 48 h $(p<0,0001)$, el cual controló el crecimiento bacteriano de patógenos y permitió un crecimiento final de bacterias ácido lácticas de $99 \times 10^{6} \mathrm{UFC} / \mathrm{mL}$, para su uso como aditivo microbiano, como acelerante biológico en los procesos de fermentación y, posiblemente, como probiótico para la alimentación animal.
\end{abstract}

Palabras clave: aditivos microbianos; bacterias ácido lácticas; inoculantes; preparados microbianos.

1 Ph.D.(c) Universidad Pedagógica y Tecnológica de Colombia (Tunja-Boyacá, Colombia). luis.borras@uptc.edu.co.

2 Ph.D. Instituto de Ciencia Animal (Mayabeque, Cuba). evalino@ica.cu.

3 Mg. Universidad Pedagógica y Tecnológica de Colombia (Tunja-Boyacá, Colombia). carlos.rodriguez@uptc.edu.co. 


\begin{abstract}
The objective of this study was to develop a microbial preparation, starting from an elaborated yogurt, based on a lactic acid bacteria (BAL) culture of medium and fast acidification, Lactobacillus delbrueckii ssp bulgaricus and Streptococcust hermophilus, from a commercial lyophilized culture (Liofast Y452B, SACCO $\left.{ }^{\circledR}\right)$. For the $\mathrm{pH}$ microbial preparation, an ANOVA analysis was carried out, by dividing the fermentation in 6 time intervals $(0,6,12,24,36$ and 48 hours) with three replicates. The inoculum preparation started from the elaboration of the yogurt, which was prepared with whole cow's milk, heated to $45{ }^{\circ} \mathrm{C}$, and inoculated with lactic acid bacteria culture. The final product showed a $\mathrm{pH}$ of 4.63 at $48 \mathrm{~h},(\mathrm{p}<0.0001)$; this product controlled the bacterial pathogens growth, and allowed a lactic acid bacteria final growth of $99 \times 10^{6} \mathrm{UFC} / \mathrm{mL}$, to be used as microbial additive and as biological accelerator in fermentation processes, and possibly as a probiotic use for animal feed.
\end{abstract}

Keywords: inoculants; lactic acid bacteria; microbial additives; microbial preparations.

\title{
Cómo citar este artículo:
}

Borrás-Sandoval LM, Valiño-Cabrera EC, Rodríguez-Molano CE. Preparado microbiano con actividad ácido láctica como acelerante biológico en los procesos de fermentación para alimento animal. Rev. Cien. Agri. 2017; 14(1): 7-13. 


\section{Introducción}

Mediante la adición de preparados microbianos ricos en bacterias ácido lácticas (BAL) es posible modificar o alterar los procesos fermentativos sólidos, con el fin de mejorar la calidad e inocuidad de estos. Al respecto, se presenta el desarrollo de un producto biológicamente activo, denominado VITAFER ${ }^{\circledR}$, que está compuesto por lactobacilos, levaduras, ácidos orgánicos de cadena corta y $\mathrm{pH}$ bajo, y es capaz de controlar el desarrollo de patógenos como Escherichia Coli y de reducir apreciablemente la incidencia de diarreas, aumentar la ganancia de peso vivo e incrementar la retención de energía y nitrógeno en los animales (1).

Se han aislado y caracterizado cepas de BAL a partir de preparados microbianos nativos elaborados a base de residuos agroindustriales (como suero de leche, estiércol bovino y contenido ruminal) y diseñados como inoculantes biológicos para procesos de ensilaje de residuales orgánicos; además, se ha propuesto que podían ser estudiados otros residuos de cosechas con este tipo de inoculantes (2).

La mayoría de las BAL son mesofílicas, aunque algunas son capaces de crecer a temperaturas de $5{ }^{\circ} \mathrm{C}$ y otras a $45{ }^{\circ} \mathrm{C}$; toleran bien concentraciones relativamente altas de ácidos y valores de $\mathrm{pH}$ más bajos que el resto de bacterias; algunas pueden crecer a $\mathrm{pH}$ de 3 , otras entre 6 y 9 , pero la mayoría crece a un $\mathrm{pH}$ entre 4 y 4,5 , por lo que pueden ser desplazadas de los hábitats que colonizan (3).

Para que un organismo sea considerado probiótico debe cumplir, primero, una caracterización in vitro, la cual contemplará estabilidad fenotípica y genotípica, seguida de patrones de utilización de carbohidratos y proteínas, tales como resistencia a la acidez gástrica y a la bilis, adhesión al epitelio intestinal, resistencia a lisozima y capacidad de utilizar prebióticos; estos dos últimos pueden ser opcionales. Además, pruebas o ensayos in vivo e in vitro que demuestren el o los efectos probióticos adjudicados, y no presentar resistencia a antibióticos ni determinantes de patogenicidad (4).

El objetivo de este trabajo fue desarrollar un preparado microbiano a partir de un yogurt elaborado con base en un cultivo de bacterias ácido lácticas (BAL). El Grupo de investigación pretende con el presente trabajo dar inicio a una línea de investigación en desarrollo de preparados microbianos con potencial uso en la alimentación animal.

\section{Materiales y métodos}

\section{A. Microorganismos}

Basado en un cultivo de BAL heterofermentativas de mediana y rápida acidificación: Lactobacillus delbrueckii ssp bulgaricus y Streptococcus thermophilus (comercial liofilizado, Liofast Y452B, $\left.\mathrm{SACCO}{ }^{\circledR}\right)$.

\section{B. Preparación del inóculo}

La preparación del inóculo parte de la elaboración del yogurt, que se hizo con leche entera de vaca, se calentó a $45^{\circ} \mathrm{C}$ y se inoculó con el cultivo de BAL, llevándose a una cava de poliespuma (icopor) para el mantenimiento de la temperatura durante 6-8 $\mathrm{h}$.

\section{Preparado microbiano}

Una vez obtenido el yogurt se procedió a mezclarlo con los componentes descritos en la Tabla I, se llevó a un volumen final con agua corriente (solvente del sistema) y se incubó a una temperatura ambiente promedio de $15{ }^{\circ} \mathrm{C}$ durante 48 horas, hasta alcanzar estabilización del pH a 4,5, con agitación 3 veces al día por 20 minutos. 
Tabla I. Componentes del preparado microbiano con actividad ácido láctica.

\begin{tabular}{|l|l|}
\hline \multicolumn{1}{|c|}{ Componentes del preparado microbiano } & \multicolumn{1}{c|}{ Aportes de los componentes } \\
\hline Melaza & Fuente de azúcares fermentables \\
\hline Harina de maíz & Fuente de energía \\
\hline Harina de fíijol & Fuente de proteína \\
\hline Urea & Fuente NNP* para la fermentación \\
\hline Sulfato de Mg & Fuente de azufre \\
\hline Premezcla mineral (bovinos) & Fuente de elementos inorgánicos y minerales \\
\hline Inóculo (Yogurt) & Fuente de BAL \\
\hline Agua & Solvente del sistema \\
\hline
\end{tabular}

*Nitrógeno no proteico.

\section{Análisis microbiológico}

Se le realizó análisis microbiológico al preparado microbiano a las $48 \mathrm{~h}$ de fermentación en un laboratorio certificado de Control Microbiológico ubicado en Boyacá, Colombia; para aerobios mesófilos (UFC/mL), (AOAC 966.23.C: 2001); coliformes totales (NMP), (ICMSF NMP: 2000); coliformes totales y fecales (NMP), (ICMSF NMP: 2000); esporas de Clostridium Sulfito reductor (UFC/ml), (ISO 15213: 2003); hongos y levaduras (UFC/g), (ISO 7954: 1987); Salmonella (AS 5013.10: 2009), y bacterias ácido lácticas (NTC 5034: 2002).

\section{E. Análisis estadístico}

Para el $\mathrm{pH}$ del preparado microbiano se realizó análisis de ANOVA, medido en 6 tiempos de fermentación $(0,6,12,24,36$ y 48 horas), con tres repeticiones a temperatura ambiente. El paquete estadístico utilizado fue INFOSTAT, versión 2012 (5).

\section{Resultados y discusión}

Las BAL están ampliamente distribuidas en la naturaleza y han sido aisladas de diversos ambientes (6). En la Tabla Il se muestran los resultados del análisis microbiológico realizado al preparado microbial; como se observa, existe una alta concentración de BAL. Las BAL empleadas para este estudio son del género Lactobacillus y Streptococcus; para su multiplicación requieren de azúcares como glucosa y lactosa, además de aminoácidos, vitaminas y otros factores de crecimiento. La leche es el medio típico y satisfactorio para la proliferación de las BAL, excelentes medio de crecimiento y producción de metabolitos (7). Estas bacterias son generalmente consideradas sanitariamente seguras; es por ello que se escogieron como cultivos iniciadores del inóculo para el preparado microbial.

Tabla II. Análisis microbiológico preparado microbiano con actividad ácido láctica.

\begin{tabular}{|l|l|}
\hline \multicolumn{1}{|c|}{ Análisis microbiológico } & \multicolumn{1}{c|}{ Conteo microbiano } \\
\hline Aerobios mesófilos & $50 \times 10^{6} \mathrm{UFC} / \mathrm{mL}$ \\
\hline Coliformes totales & $>1.100 \mathrm{NMP}$ \\
\hline Coliformes fecales & $23 \mathrm{NMP}$ \\
\hline $\begin{array}{l}\text { Esporas Clostridium } \\
\text { Sulfito reductor }\end{array}$ & $<10 \mathrm{UFC} / \mathrm{ml}$ \\
\hline Hongos y levaduras & $\begin{array}{l}\text { Hongos: } 20 \\
\text { Levaduras: } 11 \times 10^{3} \mathrm{UFC} / \mathrm{g}\end{array}$ \\
\hline Salmonella & Ausente \\
\hline Bacterias ácido lácticas & $99 \times 10^{6} \mathrm{UFC} / \mathrm{ml}$ \\
\hline
\end{tabular}


*Número más probable

Se observan en estos resultados recuentos de bacterias aerobias mesófilas, que en un proceso de fermentación expresan la carga total de microorganismos en presencia de oxígeno y a temperaturas que oscilan entre 15 y $45{ }^{\circ} \mathrm{C}$; su importancia radica en que expresan la actividad microbiana total en un proceso de tipo biológico (8).

Los resultados muestran la presencia de levaduras y hongos en número permisible con efecto benéfico para el posterior proceso fermentativo. Estudios consultados manifiestan que todos los preparados microbianos evidencian la presencia de consorcios microbianos y no de especies únicas de BAL, lo cual presenta ventajas posteriores en la inoculación en los procesos fermentativos, como el ensilaje (2). En el preparado microbial desarrollado no hay presencia de esporas de Clostridium, al igual que no se detectó presencia de Salmonella, resultado que avala su inocuidad para utilizarlo como inóculo. Estudios con BAL han planteado que cuando se utilizan lactobacilos (L. reuterii) presentes en el tracto gastrointestinal, así como en los productos cárnicos, y se sintetiza reuterina ( $\beta$-hidroxipropionaldehído) en cantidades superiores a la que el lactobacilo es capaz de reducir, el exceso se excreta al medio (9). La reuterina es un metabolito neutro y se asocia directamente con el metabolismo del glicerol; además, tiene amplio espectro de inhibición, es activa frente a microorganismos del género Salmonella, Shigella, Clostridium, Staphylococcus, Listeria y Candida y frente a algunos protozoos como Trypanosoma. Esta sustancia actúa inhibiendo la enzima ribonucleótido reductasa, que cataliza el primer paso en la síntesis de ADN, lo que explicaría su amplio espectro de actividad; además, las BAL producen una serie de sustancias antimicrobianas, entre las que se encuentran el peróxido de hidrógeno $\left(\mathrm{H}_{2} \mathrm{O}_{2}\right)$, el diacetilo, la reuterina, los ácidos orgánicos (como el láctico y el acético), y las sustancias de naturaleza proteica conocidas como bacteriocinas $(10,11$ y 12$)$.

Durante el proceso de elaboración del preparado microbiano se midió la concentración hidrogeniónica para garantizar la estabilidad del $\mathrm{pH}$ hasta el final del proceso, como se observa en la Figura I. El pH en las primeras horas se incrementó hasta valores de $\mathrm{pH}=6,11$; después de las $24 \mathrm{~h}$ se inicia un rápido descenso hasta valores de 4,56, a las $48 \mathrm{~h}$, debido a la actividad microbiana con el predominio de las BAL.

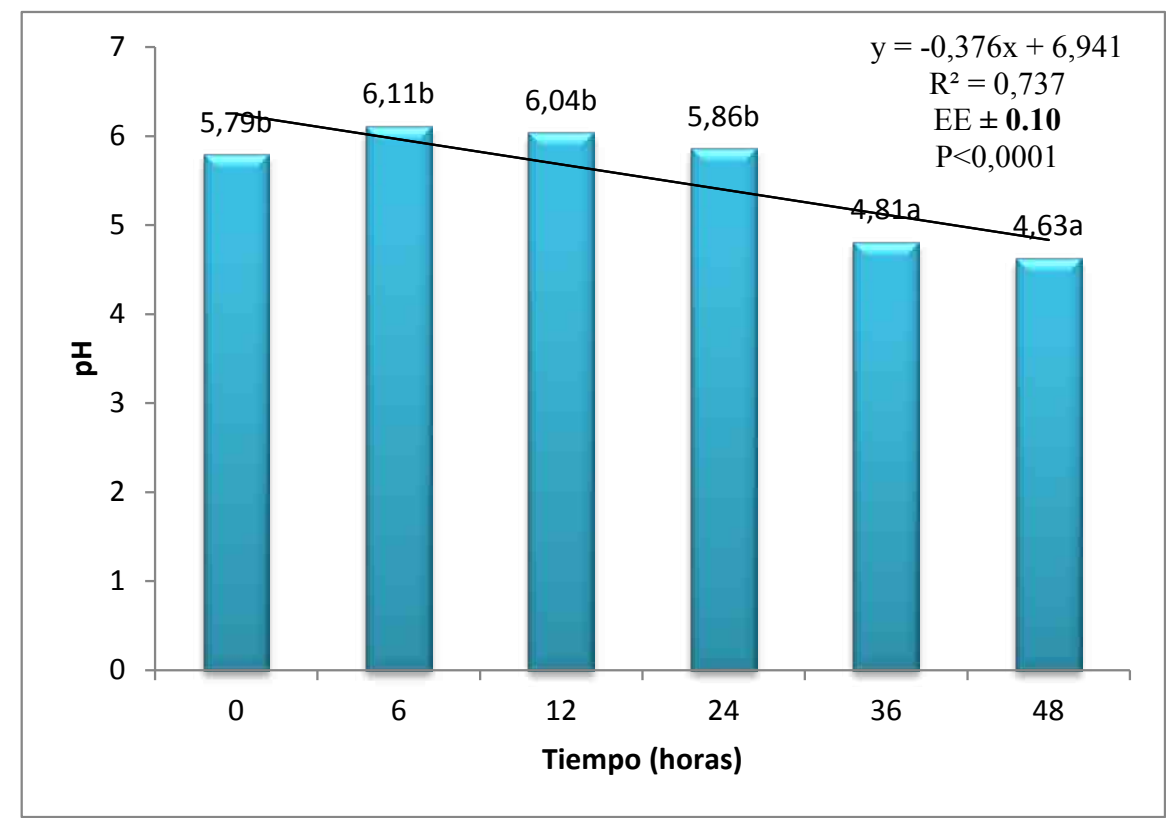

Fig. 1. Comportamiento del pH en el preparado microbial durante $48 \mathrm{~h}$ de estabilización del proceso. 
Trabajos similares muestran varios preparados microbianos que redujeron el $\mathrm{pH}$ a las 48 y 96 horas, con diferentes temperaturas del lugar de la investigación: $26^{\circ} \mathrm{C}$ y $16^{\circ} \mathrm{C}$, respectivamente (13, 14), comportamiento similar al presente trabajo, donde se observó el descenso del $\mathrm{pH}$ progresivo hasta las 48 h, cuando se estabilizó; sin embargo, en un trabajo realizado en el Ecuador encontraron una tendencia diferente, donde el $\mathrm{pH}$ sube inicialmente a la hora 8 del proceso, para luego descender lentamente hacia el final de la fermentación (96 h), con una temperatura ambiental de $14{ }^{\circ} \mathrm{C}$ del lugar de la investigación, condiciones similares a las descritas para este trabajo (2).

En conclusión, el pH bajo encontrado, 4,63, fue capaz de limitar el crecimiento de patógenos; además de las características descritas de alta concentración de BAL, una población menor de 106 UFC.mL-1 de hongos y levaduras son características por las cuales se previó un buen rendimiento como inoculantes microbianos especialmente para procesos fermentativos.

Por otro lado, el preparado microbiano presenta una población final de $99 \times 10^{6} \mathrm{UFC} / \mathrm{mL}$ de BAL a las $48 \mathrm{~h}$, lo cual expresa un potencial inoculante probiótico; esto se puede inferir de la respuesta obtenida en un trabajo de preparados microbianos con dosis de $15 \mathrm{ml}$ por animal por $\mathrm{kg} / \mathrm{pv}$, correspondiente a $6,0 \times 10^{7}$ de UFC de BAL, que incrementó su eficacia en la respuesta productiva y sanitaria durante la etapa de posdestete porcino (15).

\section{Conclusión}

El preparado microbiano desarrollado tiene efecto benéfico para el proceso de fermentación y ausencia de patógenos potenciales producto de la acidez del medio, características que avalan su calidad para utilizarlo como inóculo. Las características anteriores podrían dar un posible potencial probiótico, todo esto aplicado en la alimentación animal.

\section{Referencias}

(1) Elías A., Herrera FR. Producción de alimentos para animales a través de procesos biotecnológicos sencillos con el empleo de microorganismos beneficiosos activados (MEBA). Rev. Cuban Journal of Agricultural Science. 2008; 41(1): 8-13.

(2) Díaz B., Elias A., Valiño E. Consorcios microbianos con actividad ácido-láctica promisoria aislados desde inoculantes bacterianos nativos para ensilajes. Rev. Ciencia y Agricultura. 2014; 11(1): 17-25. DOI: http://doi.org/10.19053/01228420.3484.

(3) Jay JM. Modern food microbiology, 6th edition. Aspen publication. Gaithersburg, Maryland, USA. 2000; 45-46. DOI: http://doi.org/10.1007/978-14615-4427-2.

(4) FAO. Los Probióticos-Agentes beneficiosos para la salud. CERELA. Disponible en http://www.cerela. org.ar/ciencia/probioticos.htm. [Consultado en diciembre 2015]. 2001.

(5) Di Rienzo JA, Casanoves F., Balzarini MG, Gonzalez L., Tablada M., Robledo CW. InfoStat versión 2012. Grupo InfoStat, FCA, Universidad Nacional de Córdoba, Argentina.

(6) Azadnia P., Zamani MH, Shah G., Khalegh M., Karimi M., Taarof N. Isolation and identification of thermophilic Lactobacilli from tradicional yogurts of tribes of Kaserum. Journal of Animal and Veterinary Advances. 2011; 10: 774-776. DOI: http:// doi.org/10.3923/javaa.2011.774.776.

(7) Vásquez S., Suárez H., Zapata S. Utilización de sustancias antimicrobianas producidas por bacterias ácido lácticas en la conservación de la carne. Revista Chilena de Nutrición. 2009; 36: 64-71.

(8) Nkosi B., Meeskeb R. Effects of ensiling totally mixed potato hash ration with or without a heterofermentative bacterial inoculant on silage fermentation, aerobic stability, growth performance and digestibility in lambs. Animal Feed Science and Technology. 2010; 161: 38-48. DOI: http://doi. org/10.1016/j.anifeedsci.2010.07.015.

(9) Requena T., Peláez C. Revisión: Actividad antimicrobiana de bacterias lácticas. Producción de bacteriocinas. Rev. Española Cienc. Tecnol. Alimentos. 1995; 35: 19-44.

(10) Ávila FA, Paulillo AC, Schocken RP, Lucas FA, Orgaz A., Quintana J. A comparative study of the efficiency of a probiotic and the anti-K99 and anti-A14 vaccines in the control of diarrhea in calves 
in Brazil. Rev. Elev. Med. Vet. Pays. Trop. 1995; 48: 239-243.

(11) Rolfe R. The role of probiotic cultures in the control of gastroint. J Nutr. 2000; 130: 396-402.

(12) González B., Gómez M., Jiménez Z. Bacteriocinas de probióticos. RESPYN. 2003; 4(2): 396-402.

(13) Auquilla R. Aprovechamiento biotecnológico de residuos agroindustriales para alimentación de rumiantes. Tesis de grado. ESPOCH. Riobamba, Ecuador. 2002.
(14) Veloz V. Evaluación de ensilaje de residuos agroindustriales en bovinos de carne. Tesis de grado. ESPOCH, Riobamba, Ecuador. 2004.

(15) Flores L., García Y., Proaño F., Caicedo W. Evaluación de tres dosis de un preparado microbiano, obtenido en Ecuador, en la respuesta productiva y sanitaria de cerdos en posdestete. Rev. Ciencia y Agricultura. 2015; 12(2): 59-70. DOI: http://doi. org/10.19053/01228420.4392. 